\section{Original Article}

\title{
Oxidative stress in patients with laryngeal carcinoma
}

\author{
Dwivedi RC1,2, Raturi DP1, Kandpal N1, Dwivedi RC³, Singh RP4, Puri VN4 \\ ${ }^{1}$ Department of Otorhinolaryngology, K.G.M.U., Lucknow, India, ${ }^{2} \mathrm{Head}-\mathrm{Neck}$ Unit, \\ Royal Marsden Hospital, Fulham Road, London, SW3 6JJ, UK, ${ }^{3}$ Department of Internal Medicine, \\ University of Mannitoba, Winnipeg, Canada, ${ }^{4}$ Division of Pharmacology, C.D.R.I., Lucknow, India.
}

Correspondence to: Dr. Raghav Dwivedi, E-mail: raghav_dwivedi@rediffmail.com

\begin{abstract}
BACKGROUND: Cancer is a multifactorial disease. Repetitive cumulative damage of cellular organelles by oxy-free radicals are few of the important causative factors. AIM: To assess the role of oxidative stress in the laryngeal cancer patients in Indian population. SETTING AND DESIGN: Case control study. MATERIALS AND METHODS: Level of malondialdehyde (MDA) as a marker of oxidative stress was examined in large cohort of control (50) and laryngeal carcinoma patients (155) from North India. Both the controls and laryngeal carcinoma patients were smokers. RESULTS: In control healthy subjects MDA levels were $0.102 \pm 0.07(0.080-0.303,95 \% \mathrm{Cl}) \mathrm{n} \mathrm{mol} / \mathrm{ml}$, as compared to $0.329 \pm 0.16(0.124-0.354,95 \%$ $\mathrm{Cl}) \mathrm{n} \mathrm{mol} / \mathrm{ml}$ in the cases of laryngeal carcinoma patients. Three times higher serum MDA levels indicated that there was significant oxidative stress in the subjects having laryngeal carcinoma lesions. In addition patients with secondaries were having MDA levels of $0.4 \pm 0.02(0.391-0.40895 \% \mathrm{Cl}) \mathrm{n} \mathrm{mol} / \mathrm{ml}$, as compared to $0.57 \pm 0.03(0.558-0.58295 \% \mathrm{Cl}) \mathrm{n} \mathrm{mol} /$ $\mathrm{ml}$ in group of patients without secondaries. These two values were statistically significant as compared to control values $(P<0.01)$. CONCLUSION: These findings suggest that in case of laryngeal carcinoma patients, there is increase in the level of oxidative enzyme MDA. The oxidative stress might be due to the modulation of pro-oxidant or anti-oxidant systems in laryngeal carcinoma.
\end{abstract}

Key words: Laryngeal carcinoma, malondialdehyde, oxidative stress

\section{Introduction}

More than 5,00,000 new cases of head and neck cancers including laryngeal carcinoma are reported annually worldwide. Oxidative stress involvement in several types of cancers and cardiovascular diseases has been reported from several countries around the globe. ${ }^{[1-8]} \mathrm{L}$ aryngeal cancer in Indian population is among one of the highest reported in Asian sub continent. ${ }^{[9]}$ Free radicals and excess of electrons are known to modulate cell membrane and nuclear reactions inside the living cells. Cancerous cells have been shown to express higher activity, resulting in rapid growth of cells. Pro-oxidants are known to modulate prooxidant genes, which are related to cell growth and differentiation. These changes lead to changes in DNA structure, which initiate and maintain carcinogenic process even in cases of laryngeal cancers. ${ }^{[10]}$ Several nutrients and environmental factors are shown to be involved in the initiation and progression of cancers.
In Indian subjects it has been reported that vitamin A levels are lowered in patients of laryngeal carcinoma as compared to controls. ${ }^{[11]}$ In our institution, similar kind of observations have been made in $\mathrm{N}$ orth Indian subjects. In addition we have also reported higher angiogenic activity in these patients. ${ }^{[5]}$ Taysi et al, have reported that oxidative stress is increased in advanced laryngeal cancer patients. ${ }^{[4]}$

\section{Materials and Methods}

Patients attending the out-patients department of 0 torhiolaryngology and head and neck surgery and/ or those, admitted in the surgical/ medical wards with histopathologically proven laryngeal cancer were included in this study. Approval of this project proposal was obtained from the ethics committee of the medical school. Present study included control group $(n=50)$, 41 males and 9 females with men age of $49 \pm 4.4$ years. Patients group consisted of $(n=155)$ patients 
of laryngeal carcinoma, 128 males and 27 females with mean age of $53 \pm 6.9$ years. Controls as well as laryngeal carcinoma patients were smokers. In men in controls and laryngeal cancer subjects there was positive history of tobacco chewing or smoking or both for more than 20 years. Five women in both the groups were also reported addicted to smoking Beedis (15-20/day) or chewing tobacco for over 20 years. All the patients were from north Indian cities and their nutrition history was approximately the same. $\mathrm{H}$ emoglobin, blood sugar and blood urea in controls and study groups were done by standard methods. Patients with associated illness (hypertension, myocardial infraction, renal, hepatic, pancreatic and pulmonary diseases), which are known to alter the reactive oxygen species were excluded from study. Patients were staged and classified as described in TNM classification (UICC). From this chart we made 2 groups of patients. ${ }^{[12]}$ Laryngeal carcinoma with nodal involvement (with secondary) and those without nodal involvement (without secondary), 26 patients were included in the either group.

\section{Estimation of MDA}

$5 \mathrm{ml}$ of blood was withdrawn from the antecubital vein of controls and patients. Blood was kept in refrigerator at $4{ }^{\circ} \mathrm{C}$ and transported to Central Drug Research Institute (C.D.R.I.) for separation of serum. Whole blood was centrifuged (5000 r.p.m for 5 mins) and serum was separated and stored at $-4^{\circ} \mathrm{C}$, Serum malondialdehyde levels were estimated by O hkawa et al method and values were expressed as $\mathrm{nmol} / \mathrm{ml}{ }^{[13]}$

\section{Statistical analysis}

All the results were expressed as average value of mean \pm S.E.M., statistical analysis was done by Students $t^{\prime}$ test. Data from the control subjects was compared with laryngeal carcinoma patients and a value of $\mathrm{P}<0.05$ was considered as statistically significant.

\section{Results}

Fifty control subjects ( 41 males and 9 females) with mean age $49 \pm 4.4$ years and one hundred and 55 laryngeal carcinoma patients (128 males and 27 females) were included in this study. Eighty eight percent male patients were addicted to tobacco (Beedi, cigarette) for 20 years or more, while $12 \%$ male were not addicted. Female patients were not addicted except two females who smoked H ukka, Beedis and tobacco for the last 20 years. Control subjects were also addicted to similar type of tobacco products for 20 years or more. Control and patients groups were either vegetarian or non-vegetarian. Caloric intake in control subjects was about 2400 calories while in patients group it varied from 1200 to
1600 calories. In 50 control subjects serum M DA levels were $0.102 \pm 0.07 \mathrm{nmol} / \mathrm{ml}$, with $95 \% \mathrm{Cl} .(0.080-0.303)$ while MDA levels were three times higher $0.329 \pm 0.16$ $\mathrm{nmol} / \mathrm{ml}$ with $95 \% \mathrm{Cl} .(0.124-0.354)$, in the patients with carcinoma of larynx, the difference between the two groups was statistically highly significant $(P<0.001)$ [Table 1].

In two groups of patients $(n=26)$ without secondary and with secondary according to TNM classification were included in this study. Serum MDA levels in control and Laryngeal Carcinoma patients are shown in the [Table 2]. In control subjects serum MDA levels were $0.10 \pm 0.03 \mathrm{nmol} / \mathrm{ml}$ with $95 \% \mathrm{Cl}$. (0.082-0.118) while there times higher levels were found in laryngeal carcinoma patients without secondaries $0.40 \pm 0.02 \mathrm{nmol} /$ $\mathrm{ml}$ with $95 \% \mathrm{Cl}$. (0.391-0.408), the differences between control and laryngeal carcinoma patients were statistically highly significant $(P<0.001)$. H owever, serum MDA levels in patients with secondaries were $0.57 \pm 0.03$ $\mathrm{nmol} / \mathrm{ml}$ with $95 \% \mathrm{Cl}$. (0.558-0.582) and values were statistically highly significant when compared with values observed in control subjects $(P<0.001)$.

\section{Discussion}

The TNM (Tumor, Node, M etastasis) classification of laryngeal carcinoma integrates clinical presentation including that obtained by pathology, endoscopy and radiological evaluation in our cohort. Increased production of reactive oxygen species (ROS) has been reported in different cancers in several studies. ${ }^{[2]}$ Increased levels

Table 1: Serum malondialdehyde levels in
controls and laryngeal carcinoma patients

\begin{tabular}{lccc}
\hline Study group & (n) & MDA $(\mathbf{n m o l} / \mathrm{ml})$ & $\mathbf{9 5 \%}$ C.I. \\
\hline Controls & 50 & $0.102 \pm 0.07$ & $0.080-0.303$ \\
\hline Laryngeal carcinoma & 155 & $0.329 \pm 0.16^{\star}$ & $0.124-0.354$ \\
patients & & & \\
\hline C.I.: Confidence interval, ${ }^{*}>00.001$, MDA: Malondialdehyde
\end{tabular}

Table 2: Serum malondialdehyde levels ( $\mathrm{n} \mathrm{mol} /$ $\mathrm{ml}$ ) in controls and patients with laryngeal carcinoma with and without secondary

\begin{tabular}{lcc}
\hline Group $(\mathrm{n})$ & MDA $(\mathrm{nmol} / \mathrm{ml})$ & $\mathbf{9 5 \%}$ C.I. \\
\hline Controls $(\mathrm{n}=15)$ & $0.10 \pm 0.03$ & $0.082-0.118$ \\
\hline $\begin{array}{l}\text { Larynegeal carcinoma } \\
\text { patients without }\end{array}$ & $0.40 \pm 0.02^{*}$ & $0.391-0.408$ \\
secondary $(\mathrm{n}=26)$ & & \\
\hline $\begin{array}{l}\text { Laryngeal carcinoma } \\
\text { patients with secondary }(\mathrm{n}=26)\end{array}$ & $0.57 \pm 0.03^{*}$ & $0.558-0.582$ \\
\hline C.I.: Confidence interval, ${ }^{*} P<0.001$, MDA: Malondialdehyde &
\end{tabular}

Indian Journal of Cancer | July-September 2008 | Volume 45 | Issue 3 
of ROS could be due to increased production or reduced activity of antioxidant enzymes (Glutathione $\&$ catalase). In laryngeal carcinoma it has not been worked out as yet that which is the first stage and how the molecular events get started. In most of the studies malondialdehyde as a marker of ROS, has been measured, so as to conclude their involvement in laryngeal cancers. In our previous study in small number of patients, increased serum MDA level were observed. From this study where we have large cohort it is once again confirmed that MDA levels are higher in Laryngeal carcinoma patients probably for the first time. We have observed that laryngeal carcinoma patients have lower levels of anti oxidant ( $V$ it $A$ ), suggesting that higher MDA levels could be due to decreased activity of anti oxidant system. However, no of patients included in our study were small so there is need to expand such studies in bigger cohort. ${ }^{[5]}$ We separated two group of patients one with nodal involvement and the other one without the secondaries. It was observed that there was not significant difference in the two groups. These findings suggest that ROS starts up regulating during the process of tumor initiation. It will be interesting to have continuous studies with different stages of cell cycle and ROS production. We do not have any study to show the role of antioxidant in the treatment of laryngeal carcinoma patients. However, several studies have shown that beta carotene has a curative effect on different cancers. ${ }^{[14]}$ B eta carotene, vitamin $A$ and other vitamins like $C$ and $E$ have antioxidant activity, therefore it has been reported from international studies in the cancer that retinoids have cancer preventing capabilities. ${ }^{[14-16]}$ Tumor invasion, metastasis and angiogenesis are the important events in carcinogenesis and how antioxidants modulate these processes still needs to be explored in detail. Now even in our previous study we reported that serum Angiotensin Converting Enzyme (ACE) activity is enhanced in cases of laryngeal carcinoma suggesting that renin angiotensin peptides might also be playing some important role in angiogenic process of tumor progression. ${ }^{[5]}$ We have al ready started clinical trials with ACE inhibitors in our laryngeal carcinoma patients and the results are eagerly awaited.

Tobacco consumption in various forms by oral intake or inhalation is the strong exogenous source for the generation of ROS. Oxidative stress activates the production of procarcinogenic compounds ex. Benzopyrenes. In addition these reactants also damage the cellular DNA Pryor. ${ }^{[17]}$ It could be concluded that these factors are operative in initiation of laryngeal carcinoma in our cohort. It will be very interesting to address the many questions related to the area of mutagenesis and biomarkers. It thus concluded that patient of laryngeal carcinoma from $\mathrm{N}$ orthern India have increased burden of reactive oxygen species. H owever, mechanism related to oxidant stress and antioxidant system remains to be clarified.

\section{Acknowledgments}

The authors would like to thank Dr. Namita Kanwar, Dr. Sumit Kumar and Dr. Ehtesham Siddiqui for their support in manuscript preparation.

\section{References}

1. Vokes EE, Ralph RW, Lippman SM, Hong WK. Head and neck cancer. N Engl J Med 1993;328:184-94.

2. Guyton KZ, Kensler TW. Oxidative mechanisms in carcinogenesis. Br Med Bull 1993;49:523-44.

3. Stich HF, Anders F. The involvement of reactive oxygen species in oral cancers of betal quid/tobacco chewers. Mutat Res 1989;214:47-61.

4. Taysi S, Ushu C, Akcay F, Subeyaz MY. Levels of MDA and NO in the plasma of patients with advance laryngeal cancer. Surg Today 2003;33:651-54

5. Kandpal N, Shukla GK, Bhatia N, Agarwal SP, Saha S, Puri VN. Oxidant, vitamin $A$ and angiogenic markers in laryngeal cancer patents. J Laryngol Otol 2003;117:871-4.

6. Vaziri ND, Wang XQ, Oveisi F, Rad B. Induction of oxidative stress by glutothione depletion causes severe hypertension in normal rats. Hypertension 2000;36:142-6.

7. Troll W, Wiesner $\mathrm{R}$. The role of oxygen radicals as a possible mechanism of tumor promotion. Annu. Rev Pharmacol Toxicol 1985;25:509-28.

8. Cai H, Harrison DG. Endothelial dysfunction in cardiovascular diseases: The role of oxidant stress. Circulation 2000;87:840-4.

9. The world health technical report, World Health Organisation. Geneva: WHO; 1997.

10. Cerutti PA. Prooxidant states and tumor promotion. Science 1985;227:375-81.

11. Kapil U, Singh P, Bahadur S, Shukla NK, Dwivedi S, Pathak P, et al. Association of Vitamin A Vitamin C Zinc with laryngeal cancers. Indian J Cancer 2003;40:67-70.

12. American Joint Committee on Cancer, Mannual for staging of cancer $3^{\text {rd }}$ ed. Philadelphia: J.B. Lippencott; 1988.

13. Ohkawa H, Ohishi N, Yagi K. Assay for lipid peroxides in animal tissues by thiobarbituric acid reaction. Anal Biochem 1997;95:351-8.

14. Sankaranarayan R, Mathew B. Retinoids as cancer preventive agents. IARC Sci Publ 1996; 139:47-59.

15. Peto R, Doll R, Buckley JD, Sporn MB. Can dietry beta carotene materially reduce Human cancer rates. Nature 1981;290:201-8.

16. Torun MY, Goene A. Serum beta carotene vitamin E Vitamin C malondialdehyde levels in several types of cancers. J Clin Pathol Ther 1995;20:259-63.

17. Pryor WA. Cigarette smoke radical and the role of free radicals in chemical carcinogenicity. Environ Health Presp 1997; 105:875-82.

Source of Support: Nil, Conflict of Interest: None declared. 